Martin Friedrich*

\title{
Using Occupations to Evaluate the Employment Effects of the German Minimum Wage
}

https://doi.org/10.1515/jbnst-2018-0085

Received September 30, 2018; revised August 27, 2019; accepted September 09, 2019

Abstract: This paper evaluates the short to medium run employment effects of the 2015 introduction of a statutory minimum wage in Germany. The effect of the policy is recovered from variation in the bite of the minimum wage across occupations using a difference-in-differences estimator. The analysis reveals that the reform only had a small impact on employment and highlights the importance of regional effect heterogeneity. In East Germany, marginal employment decreased by about 18,000 jobs in the short run and 52,000 jobs in the medium run, respectively, due to the minimum wage. In West Germany, no negative employment effects are detectable, but regular employment increased temporarily because of the reform. The medium run estimates include the impact of the first marginal increase of the wage floor from $€ 8.50$ to $€ 8.84$ in 2017.

Keywords: minimum wage, employment, jobs, occupations

JEL Classification: C23, J23, J31, J38

\section{Introduction}

On January 1, 2015, Germany introduced a universal minimum wage for the first time in the country's history. The policy was adopted in response to a gradual erosion of the collective bargaining system since the mid-1990s that led to the expansion of low-wage work (Bosch 2018). Between 1995 and 2015, the share of workers on low pay, i. e. $60 \%$ of the median wage, grew from 14 to $19 \%$, which equals a 36\% increase (OECD 2019). Many political advocates, for instance, the trade unions, saw the surge of low wage work as one of the drivers of in-work poverty. Thus, they campaigned for the introduction of a minimum wage as a social policy, which, they believed, would increase earn-

*Corresponding author: Martin Friedrich, GradAB/PASS, Institute for Employment Research (IAB),Regensburger Str. 100, Nuremberg 90478, Germany, E-mail: martin.friedrich@iab.de 
ings and reduce hardship (see, e. g. DGB 2015). Research shows indeed that the introduction of the policy led to higher hourly wages at the lower end of the distribution (Caliendo et al. 2017). However, the pay rise for some workers may have come at the cost of less jobs in the economy, which is the topic of this investigation.

According to standard economic theory, the introduction of a minimum wage into a perfectly competitive labour market creates unemployment (Brown 1999). Yet, many evaluation studies fail to find any discernible employment effects (see, e. g. Dube et al. 2010, 2016; Cengiz et al. 2019). Theoretically, this may be rationalised by monopsonistic competition (Manning 2003). Concerning the German reform, previous studies found no discernible employment effects (Ahlfeldt et al. 2018; Dustmann et al. 2019) or at most moderately negative effects (Bossler/Gerner 2019; Caliendo et al. 2018). Furthermore, some studies have identified a positive impact on regular employment, i. e. jobs that yield earnings above €450 per month, alongside a negative impact on marginal employment, i. e. jobs that pay below this threshold (Garloff 2019; Holtemöller/Pohle 2017; Schmitz 2019). Before the reform, economists warned that a universally set minimum wage might be too high and thus economically harmful for East Germany because wages there are considerably lower than in West Germany (Möller/König 2008). The evidence suggests that this concern was warranted because disemployment effects are predominately observed in East Germany (Bossler/Gerner 2019; Schmitz 2019).

My study evaluates the short to medium run employment effects of the 2015 reform and adds to the evidence about effect heterogeneity between West and East Germany. The treatment effect is recovered from variation in the affectedness of different occupations by the policy using a difference-in-differences estimator. Specifically, the variable used to capture the treatment intensity is the bite of the minimum wage, i. e. the share of workers in each occupation who earned below the new wage floor $(€ 8.50 / \mathrm{h})$ in the year before it became binding. I contribute to the literature in three ways. First, my study triangulates the existing evidence by analysing a new unique data set combining administrative and official survey data at the level of occupations. Secondly, I analyse data until the end of 2017 and, therefore, my article provides the first evidence about the consequences of the marginal increase of the minimum wage from $€ 8.50$ to $€ 8.84$ in 2017 , which was slightly higher than the inflation rate. Thirdly, the analysis focuses on effect heterogeneity between East and West Germany; for this purpose, all estimations are run separately for the two regions.

This paper shows, in line with previous studies, that the employment effects of the reform were small. The main finding is that the minimum wage affected 
marginal employment negatively, but only in East Germany. My estimates indicate that the reform caused a loss of about 20,000 jobs in the short run and 50,000 jobs in the medium run, respectively. The medium run effect also includes the impact of the 2017 marginal increase of the minimum wage. Furthermore, I find evidence that regular employment in West Germany increased temporarily just after the reform, most likely, because marginal workers were upgraded to regular jobs due to the pay rise induced by the minimum wage. However, this effect becomes statistically indistinguishable from zero in later periods.

The remainder of the paper is structured as follows: Chapter 2 informs about the institutional background of the reform, Chapter 3 reviews the existing literature, Chapter 4 describes the data and methodology used, Chapter 5 presents the results and robustness checks and Chapter 6 concludes.

\section{Institutional background \& expectations}

The German government announced the enactment of a federal minimum wage of €8.50 per hour in their coalition contract in December 2013. On July 3, 2014, the law was adopted by parliament and on January 1, 2015 it became effective. When the policy was first introduced, the economy had been growing for the fifth year in a row and employment had reached its highest level since 1990 (Federal Statistical Office 2016a). It was agreed that an independent commission of experts would make recommendations to the government about future increases of the wage floor. Since then it has been increased twice: to $€ 8.84$ in January 2017 and to €9.19 in January 2019. The 2017 increase of the minimum wage (by 4\%) was higher than the inflation rate from 2015 up to the reform (2\%) (Federal Statistical Office 2019).

More than half of the four million workers who were directly affected by the reform were marginally employed (Federal Statistical Office 2016b). Jobs qualify as marginal employment if they yield gross monthly earnings of $€ 450$ or less. This type of work is exempted from social security contributions. Thus, a person who is exclusively marginally employed must find health insurance autonomously and is only entitled to a minimum of benefits in case of unemployment. Jobs are regarded as regular employment if they yield gross monthly earnings of more than $€ 450$ per month. Earnings from regular work are subject to social security contributions both from the worker's as well as from the employer's side. 
Prior to the introduction of the minimum wage, simulation studies predicted large disemployment effects in the range of 426,000 up to 911,000 lost jobs (see, e. g. Knabe et al. 2014). The most affected groups were expected to be marginally employed workers, especially in East Germany. At the same time, it appeared likely that some of the "lost" marginal jobs would be upgraded to regular employment because a higher hourly wage at constant working hours would lift workers above the $€ 450$ threshold (Projektgruppe Gemeinschaftsdiagnose 2014).

\section{Literature review}

\subsection{International literature}

The largest body of empirical work about the employment effects of the minimum wage studies the U.S. case where variation in the level of the minimum wage across federal states and over time can be used to evaluate the effects of the policy (see, e.g. Neumark/Wascher 1992, 2000; Card/Krueger 1994, 2000). The analyses most often focus on employment among highly affected subgroups such as teens or restaurant workers and present conflicting results depending on the data and econometric models used. Advocates of a simple two-way fixed effects model, including state and year dummies, usually find relatively small negative yet statisitically significant employment effects of minimum wage hikes (Neumark et al. 2014, 2017). Yet, critics of this approach fail to idenitify discernible employment effects when estimating more complex models and restriciting the amount of identifiying variation used to neighbouring regions (Dube et al. 2010; Allegretto et al. 2011, 2017). ${ }^{1}$

A recent paper identifies the effect of the policy on overall employment (not only for sub-groups) by comparing the amount of missing jobs just below the minimum wage compared to the number of excess jobs just above the wage floor immediately following a long series of reforms. This analysis fails to find any disemployment effects that would be statistically distinguishable from zero (Cengiz et al. 2019). Despite of the ongoing debate about the best research design to use, the U.S. literature seems to coalesce around the insight that the impact

1 They argue in favor of using models that control for spatial heterogeneity in employment trends that may be correlated with regional changes of minimum wage policy. Also, they advocate restricting the data to neighboring regions, for example, contiguous counties, to rule out the possibility of confounding unobvserved shocks to local labour markets. 
on jobs of the incremental increases of the minimum wage observed to date was neglibile or at most small.

Evidence from other countries, where major reforms were witnessed, points into a similar direction. The United Kingdom, for instance, introduced a nationwide minimum wage in 1999 and reseachers used variation in the share of workers affected by the policy across regions, commonly called the "bite" of the minimum wage, to study its impact. Most research does not find any statistically significant employment effects (Stewart 2002; Dolton et al. 2015). Further evidence from major reforms is available for Hungary (Harasztosi/Lindner 2019), Portugal (Portugal/Cardoso 2006) and Ireland (O’Neill et al. 2006). None of these investigations identifies strongly negative employment effects (relative to the observed wage effects).

\subsection{Effects of the German minimum wage on employment}

For Germany, most studies point to small negative employment effects in the short run while some studies do not find any discernible employment effects. As in the case of the United Kingdom, the effect is identified from variation in the affectedness of different firms, regions or industries by the policy. The study by Bossler and Gerner (2019), for instance, compares firms that employed minimum wage workers to a control group of firms that payed above the new wage floor before the reform. The authors estimate an increase in wages of about $4-6 \%$ and a reduction of total employment by approximately $1.7 \%$ in affected establishments. They conclude that up to 68,000 jobs were lost due to the minimum wage. The results are statistically significant and robust across a wide range of different specifications.

In contrast, Ahlfeldt et al. (2018) and Dustmann et al. (2019) do not find any discernible effects on total employment using regional-level data if they account for region-specific differences in employment trends prior to the reform. Other studies that use regional wage variation distinguish between regular and marginal employment and identify negative effects; however, usually, only the effect on marginal employment is precisely estimated (Bonin et al. 2019; Caliendo et al. 2018; Schmitz 2019). According to this set of studies, between 70,000 and 200,000 marginal jobs have been lost due to the introduction of the minimum wage. Furthermore, some studies using the regional approach recover negative effects on marginal employment, but positive effects on regular employment (Garloff 2019; Holtemöller/Pohle 2017).

The relatively small employment effects of the German reform may be explained by several adjustment mechanisms. First, research shows a negative 
effect on hours worked that may have alleviated the effect on employment headcounts (Bossler/Gerner 2019; Caliendo et al. 2017). Secondly, survey data suggests substantial non-compliance with the policy (Burauel et al. 2017). Thirdly, the affected firms seem to have partly offset higher labour costs by an increase in product prices (Link 2019). Lastly, recent research provides evidence for imperfect competition in the labour market that may explain the absence of discernible employment responses, for example, due to monopsony power, search frictions or product market frictions (Dustmann et al. 2019).

There are still ambiguities and gaps in the literature that I aim to address in my study. First, the mismatch between studies that find positive effects on regular employment and others that find adverse effects merits further investigation. Secondly, there is no evidence yet about the medium run effects of the reform and the 2017 increase. Thirdly, the evidence about whether West and East Germany were affected in the same way is to some extent ambiguous. For example, the study by Bossler and Gerner (2019) finds disemployment effects only in the East whereas Schmitz (2019) identifies negative effects on marginal employment in both West and East Germany and a positive effect on regular employment in West Germany. I present results for both regions separately in Chapter 5 to enrich the evidence on the topic.

\section{Data \& methodology}

\subsection{Data}

For this investigation, I compiled data on employment and wages in the occupations of the German national classification of occupations, called KldB 2010 (Federal Employment Agency 2011). The occupation-codes comprise five digits: the first four digits structure occupations horizontally according to the area of expertise and the fifth digit orders the occupations vertically according to the complexitiy of the tasks which are performed (Matthes/Paulus 2013).

Since the survey data on wages I use (see below) does not contain a sufficiently large sample of workers to be representative of each of the 1,282 five-digit occupations in the KldB 2010, I decided to erase the fourth digit and combine the third and the fifth digit to retain information about both the area of expertise and the task complexity. Workers in each of these 427 four digit occupations are comparable in terms of the qualifications they require (ibid.). Therefore, their wages and exposure to the minimum wage are likely similar. 
To retrieve data on employment in each occupation over time, I aggregated the universe of German social security records, which are available to researchers at the Institute for Employment Research. The population covers all dependent employees. Self-employed persons, government officials and military staff are not included. Persons who were not eligible for the minimum wage in terms of age, employment status and economic sector were excluded from the aggregation. ${ }^{2}$ Employees who hold multiple regular or marginal jobs, respectively, were only counted once per job category. If a worker held a regular and a marginal job at the same time, they count towards each category once. Employment was measured quarterly and the resulting panel data set spans from 2012 to 2017. The reference dates for the quartely measurements are: 31 March, 30 June, 30 September and 31 December.

The aggregated employment data was linked to information about the bite of the minimum wage in each occupation that stems from the Structure of Earnings Survey (VSE), a nationally representative study of 1,000,000 employees working in 60,000 businesses. The VSE is conducted every four years by the Federal Statistical Office (FSO) (2018) and records the hourly wage and KldB 2010 occupation of each respondent. Therefore, the 2014 wave of the survey can be used to obtain the pre-reform bite of the minimum wage by occupation defined as the share of employees who earned an hourly wage below $€ 8.50$ in April 2014. The data is highly reliable because it is obligatory for businesses to respond to the survey and the information they submit is mainly derived from wage accounting. To calculate the bite, the VSE sample was restricted to employees who were eligible for the minimum wage upon its enactment.

The final dataset contains complete information on employment and wages for 346 of the 427 four-digit occupations of the KldB 2010. Of the 81 left out occupations, 43 were deliberately excluded because they were not covered by the minimum wage in 2015, and 38 occupations were discarded because the VSE data does not contain a sufficiently large number of eligible workers to retrieve valid information on the bite of the minimum wage for these subgroups. ${ }^{3}$ Still, the final

2 Groups that are generally exempted from the German minimum wage are: interns, apprentices, minors without a degree, volunteers and previously long-term unemployed people in the first six months after they enter employment. Furthermore, temporary exemptions were applied to occupations in the meat industry, agriculture, forestry, gardening, hairdressing, postal services, textile industry, dry cleaning and for temporary work in East-Germany (for details see, Mindestlohnkommission 2016, p. 155).

3 Examples of occupations that the VSE does not cover sufficiently include many high skilled niche occupations such as mathematicians, biologists and conductors. Furthermore, workers in occupations that are often done by self-employed people such as photographers, psychotherapists or 
dataset covers more than $99 \%$ of all employees contained in the social security data who were eligible for the minimum wage at the time of its introduction. Thus, it can be regarded as highly representative of the target group.

\subsection{Identification strategy}

The causal effect of the minimum wage on employment is estimated using a generalised difference-in-differences approach. The idea is that the observed treatment effect varies by occupation depending on the share of workers initially earning less than the new wage floor. As opposed to a binary treatment vs. control group variable used in standard difference-in-differences analyses, this bite indicator is a measure of the treatment intensity of the policy because "each unit is put somewhere on a continuum of possible treatments" (Wooldridge 2010: 150). The causal effect is recovered using the following regression model:

$$
\ln \left(\text { empl }_{i, t, q}=\text { occ }_{i}+\text { year }_{t}+\text { quarter }_{q}+\sum_{j \neq 2014} \delta_{i, j}{ }^{\star} \text { bite }_{i}{ }^{\star} I(t=j)+\varepsilon_{i, t, q}\right.
$$

Employment (empl) in occupation $i$ is observed quarterly in logs. The year fixed effects pick up common time shocks and the coefficients of interest $\delta_{\mathrm{i}, \mathrm{j}}$ capture the annual deviations from these shocks depending on how strongly occupations were affected by the minimum wage. Since the bite variable is normalised, the coefficients can be interpreted as the percentage change in employment caused by a one standard deviation increase in the bite of the minimum wage. The occupation-fixed effects capture unobserved time-constant heterogeneity across occupations and the quarter fixed effects account for seasonality. Note that the policy variable is only included in the interaction term and not on its own because it is time-constant as it was measured once in 2014 and would therefore be omitted in the presence of occupation-fixed effects. The estimate of the policy effect in 2017 captures the effect of the first marginal increase of the minimum wage based on the assumption that the ranking of occupations w.r.t to the bite of the minimum wage did not change substantially between 2014 and 2017.

For the estimation of eq. (1), the year 2014 was chosen as the reference period. The minimum wage reform was adopted by parliament in July. Thus, firms may have already started adjusting employment before the reform became actually

music instrument makers are rarely observed in the VSE because the survey population are workers in dependable employment. As it is implied by the small number of observations in the VSE for these occupations, their share of the population that is eligible for the minimum wage is negligible. 
effective. To preclude any anticipation effects as a threat to identification, the last quarter of 2014 (September to December) is dropped from the analysis. The identification of the treatment effect hinges on the assumption that weakly and strongly treated occupations would have followed the same employment trend in the absence of the reform. This "common trends assumption" cannot be directly tested because the counterfactual is unobservable. The assumption seems plausible, however, if employment in weakly and strongly affected occupations followed the same trend before the adoption of the policy. This can be assessed graphically (see Chapter 5.1) and by estimating the $\delta_{i, j}$ coefficients of the prereform years (placebo treatment). These coefficients are expected to be statistically indistinguishable from zero because the treatment variable must not have had any effect before the reform became effective. The standard errors of the coefficient estimates are clustered at the level of occupations.

As a major robustness check of the identifying assumption, a second specification is estimated that additionally includes a linear bite-proportional time trend $\left(\right.$ bite $\left._{i}{ }^{\star} t\right)$ :

$$
\begin{aligned}
\ln (\text { empl })_{i, t, q}= & \text { occ }_{i}+\text { year }_{t}+\text { quarter }_{q}+\sum_{j \neq 2012-2014} \delta_{i, j}{ }^{\star} \text { bite }_{i}{ }^{\star} I(t=j) \\
& +\gamma_{i}{ }^{\star} \text { bite }_{i}{ }^{\star} t+\varepsilon_{i, t, q}
\end{aligned}
$$

The parameter $\gamma_{\mathrm{i}}$ is identified using the pre-policy years (2012-2014) and thus captures any underlying difference in employment trends w.r.t the (future) bite of the minimum wage that may have already prevailed before the reform. For instance, there may have been stronger job growth in low wage and high wage compared to middle wage occupations due to job polarisation (Dustmann et al. 2009). The estimates of $\delta_{i, j}$ that stem from this specification can be interpreted as causal effects assuming that the pre-reform difference captured linearly by $\gamma_{\mathrm{i}}$ would have continued in the same way in the post-reform period had the minimum wage not been introduced. This is a weaker version of the common trends assumption than in specification 1 such that the case for causality is more credibly made if estimating eqs. (1) and (2) produces similar results.

Ahlfeldt et al. (2018) and Dustmann et al. (2019) demonstrate how the estimates of the employment effects shrink towards zero when group-specific trends are included in the diff-in-diff specifications they use. This is the case because diverging pre-reform trends bias the estimator. To preclude this type of bias, I interpret the estimates of specification 2 as the preferred results. In the U.S. literature, there is some debate about whether including group-specific trends in the equation is truly an improvement (Neumark et al. 2014, 2017; Allegretto et al. 
2011, 2017). Controlling for trends may be a problem if the outcome of interest is employment growth over longer periods because they may pick up part of the treatment effect (Meer/West 2016). In the German case, however, this concern does not apply because the group-specific trends can be estimated based on the pre-reform years only. In this setting, augmenting the diff-in-diff specification with group-specific trends reveals how the post-reform outcomes deviate from pre-existing differences.

\section{Results}

\subsection{Descriptive statistics}

The occupations in the sample include 26,207,646 regularly employed (full- and part-time) workers and 6,334,790 marginally employed workers (see Table 1). As shown in Table 2 there is considerable variation in the bite of the minimum wage

Table 1: Total employment by region in June 2014 .

\begin{tabular}{lrrr}
\hline & Germany & West Germany & East Germany \\
\hline Regular employment (full- and part-time) & $26,207,646$ & $22,117,111$ & $4,090,535$ \\
Marginal employment & $6,334,790$ & $5,703,181$ & 631,609 \\
\hline
\end{tabular}

Notes - Table 1 reports the employment totals over all occupations included in the final regression sample by region. The calculations are based on workers who are eligible for the minimum wage only. Workers in occupations without valid information about the bite of the minimum wage were discarded from the sample. Data Source: Integrated Employment Biographies (IEB), own calculations.

Table 2: Summary statistics of the bite of the minimum wage and Kaitz index.

\begin{tabular}{lrrrrrr}
\hline & Mean & Median & SD & Min & Max & N \\
\hline Bite & 6.6 & 2.6 & 10.3 & 0 & 62.8 & 346 \\
Kaitz index & 51.2 & 49.0 & 18.7 & 10.24 & 112.6 & 346 \\
\hline
\end{tabular}

Notes - Table 2 displays summary statistics for the bite of the minimum wage, i. e. the share of workers who earned below $€ 8.50$ per hour, and the Kaitz index, i. e. the ratio of the minimum wage to the median wage in an occupation. The data includes 346 four-digit occupations of the KldB 2010 that were covered by the policy and for which valid information could be obtained. Data Source: Structure of Earnings Survey 2014, own calculations. 
across occupations that can be exploited to study the impact of the policy. On average, $6.6 \%$ of workers in an occupation were affected by the minimum wage reform. The median value of the bite variable is $2.6 \%$ and it ranges between 0 and $62.8 \%$. 69 of the 346 occupations, which are analysed, contain (close to) $0 \%$ of workers who earned below the minimum wage in 2014 (see Figure 1). Examples include engineers, technicians, economists and pilots. 210 occupations are weakly to moderately treated by the policy containing between $0.6-10 \%$ of workers affected. The remaining 67 occupations, which contain more than $10 \%$ of affected workers, may be considered as strongly treated. Examples include wellness services (bite $=62.8 \%$ ), facility security services (bite $=53.8 \%$ ), retail assistants (bite $=51.6 \%$ ), fishing assistants (51.3\%) and assistant waiters/waitresses (bite $=49.7 \%$ ). Table 2 also includes summary statistics of the Kaitz index, which is being used as an alternative treatment indicator in a robustness check (see Chapter 5.3).

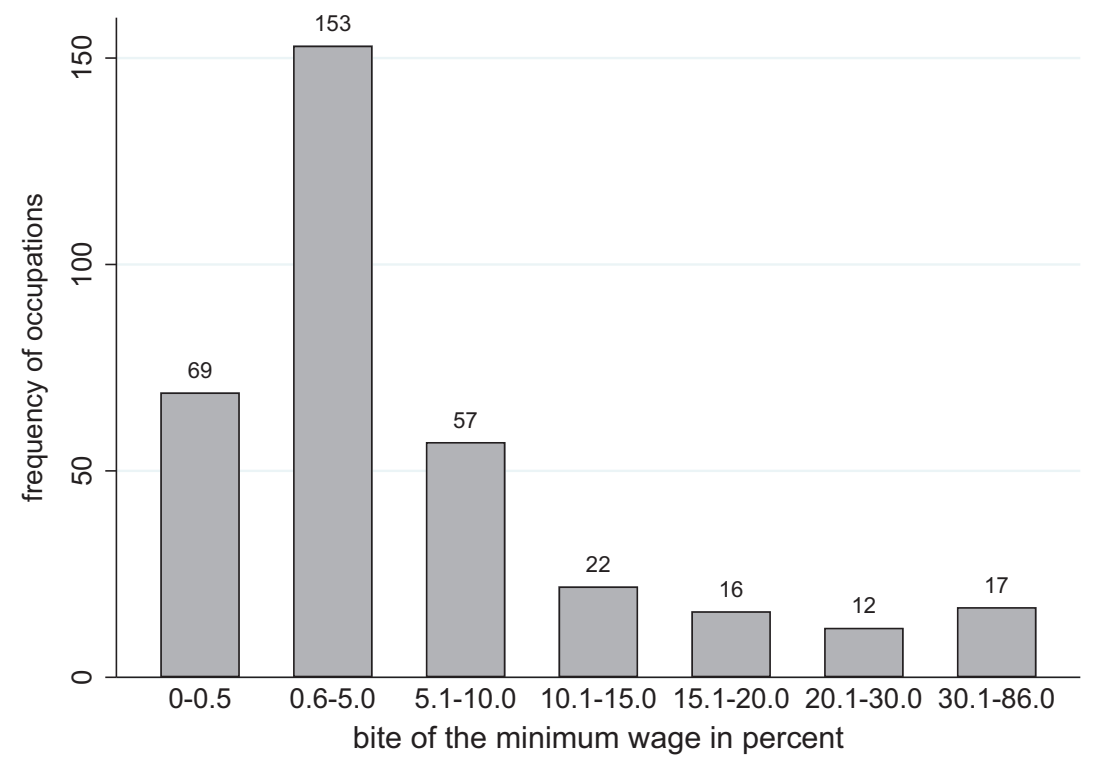

Figure 1: Frequency of occupations by the bite of the minimum wage.

Notes - Figure 1 shows the distribution of the bite of the minimum wage, i. e. the share of workers who earned below $€ 8.50$ per hour in April 2014. The continuous bite variable was divided into eight categories for the purpose of illustration. The calculations are based on eligible workers only. Occupations for which no valid information about the bite could be obtained were discarded from the sample.

Data Source: Structure of Earnings Survey 2014, own calculations. 
Figures 2 and 3 show how much regular and marginal employment, respectively, grew throughout the observation period depending on the bite of the minimum wage. The time-series have been seasonally adjusted to isolate the trend component. The occupations were divided at the median of the bite distribution into relatively weakly and strongly treated units. Comparing the employment trends that the two groups have followed before the reform, offers some intuition about the validity of the common trends assumption that underlies the subsequent estimations.

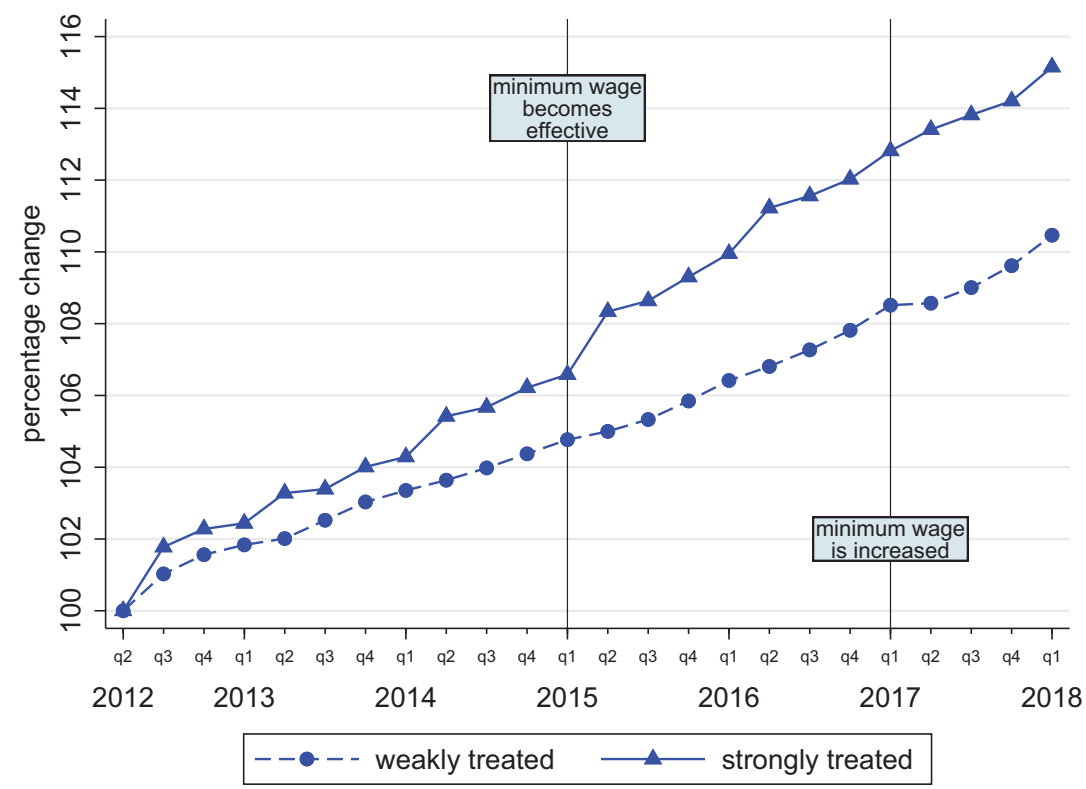

Figure 2: Growth of regular employment by the bite of the minimum wage.

Notes - Figure 2 shows the growth rate of regular employment by the bite of the minimum wage. The sample was divided into weakly and strongly treated occupations at the median of the bite distribution. Employment was measured quarterly at the following cut-off dates: 31 March (q1), 30 June (q2), 30 September (q3) and 31 December (q4). The time series was seasonally adjusted.

Data Sources: Integrated Employment Biographies (IEB) \& Structure of Earnings Survey.

Concerning regular employment (Figure 2), the trends evolve somewhat similarly in weakly and strongly treated occupations. Employment grew slightly faster in occupations, which were more affected by the minimum wage, already before the reform. At the beginning of 2015, there is a spike in regular employment. 


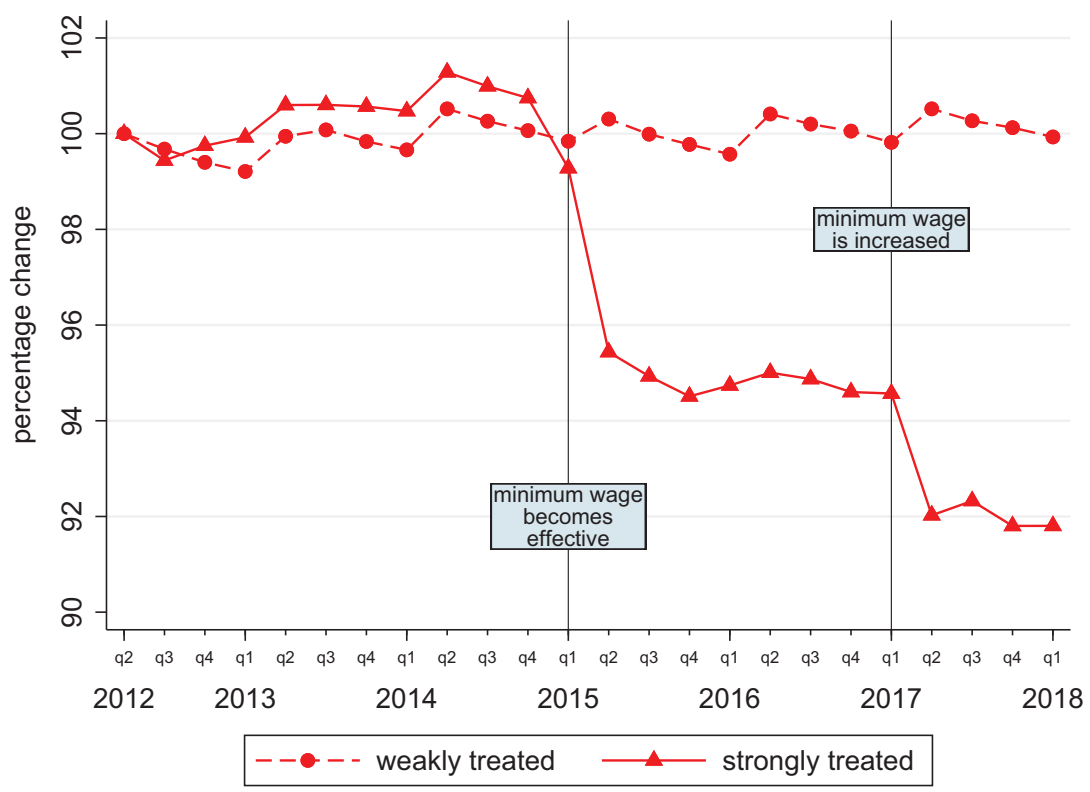

Figure 3: Growth of marginal employment by the bite of the minimum wage.

Notes - Figure 3 shows the growth rate of marginal employment by the bite of the minimum wage. The sample was divided into weakly and strongly treated occupations at the median of the bite distribution. Employment was measured quarterly at the following cut-off dates: 31 March (q1), 30 June (q2), 30 September (q3) and 31 December (q4). The time series was seasonally adjusted.

Data Sources: Integrated Employment Biographies \& Structure of Earnings Survey 2014, own calculations.

Some of it may be attributed to the introduction of the minimum wage because it is likely that the sudden increase in monthly earnings that came with the reform lifted some marginal workers above the threshold of €450 that divides marginal from regular work.

Marginal employment followed a common trend in strongly and weakly treated occupations up to September 2014, which was three months before the reform (Figure 3). From September 2014 until September 2015 marginal employment decreased by about $5 \%$ in strongly treated occupations while it stagnated in weakly treated occupations. After a short period of some slight recovery, marginal employment dropped again by about $2 \%$ when the minimum wage was increased from €8.50 to €8.84 in January 2017. Given that the data yields support for the common trends assumption, the graph suggests that the observed job loss was caused by the minimum wage reform. 


\subsection{Regression analysis}

This section presents the results of the regression analysis. The coefficients of interest capture the interaction of the year-dummies and the bite variable in the post-reform period. The effects for the pre-reform period are expected to be statistically indistinguishable from zero if the common trends assumption holds. The results are presented using coefficient plots that enable a direct visual assessment of the identifying assumption.

Figure 4 reports the results for regular employment. The baseline estimates eq. (1) are positive and statistically significantly different from zero in the postreform period. However, the placebo estimates in the pre-reform period are statistically significant as well and negative suggesting that an underlying positive trend may bias the results. Plotting an extrapolation of this trend (the green dashed line) based on the pre-reform coefficient estimates reveals that only the effect in 2015 is statistically significantly different from the underlying trend. The baseline estimates of the effect of the reform on marginal employment are statistically significant as well (Figure 5). However, they seem to be biased by an underlying negative trend as indicated by the green (dashed) line. None of these estimates are statistically significantly different from this trend.

The distance between the baseline estimates and the underlying trend may be interpreted as a more credible estimate of the causal effects of the policy. It corresponds to the de-trended treatment effect identified by eq. (2). Figure 6 plots the de-trended coefficient estimates of the effect of the minimum wage on regular employment (blue dots) and marginal employment (red triangles). The trend estimate reappears in the figure as a horizontal at zero (the green dashed line). The de-trended effects are smaller and only the effect on regular employment in 2015 is statistically significant. Accordingly, regular employment grew by about $0.5 \%$ with every one standard deviation $(\mathrm{sd}=10.3 \%)$ increase in the bite of the minimum wage in the first year. Across all occupations, this corresponds to an increase of about 110,000 jobs. ${ }^{4}$ This positive effect may reflect the expected upgrading of marginal to regular jobs as a result of wage growth (see Chapter 2). Interestingly, the estimated effect until 2017 is exactly zero. This may suggest that the initially upgraded jobs did not survive in the medium run or that the marginal increase of the minimum wage in 2017, which is also captured by the coefficient estimate, had a negative effect on regular

\footnotetext{
4 This back-of-the-envelope calculation represents the employment effect cumulated over all occupations in the sample based on the estimate of the $\delta_{j}$ parameter in eq. (2). It is obtained by using this formula: jobs $=\sum_{i}^{N}$ empl $_{i, 2014 q 2}{ }^{\star} \hat{\delta}_{j}{ }^{\star}$ bite $_{i}$. The second quarter of 2014 was chosen as the reference period for the employment measurement.
} 


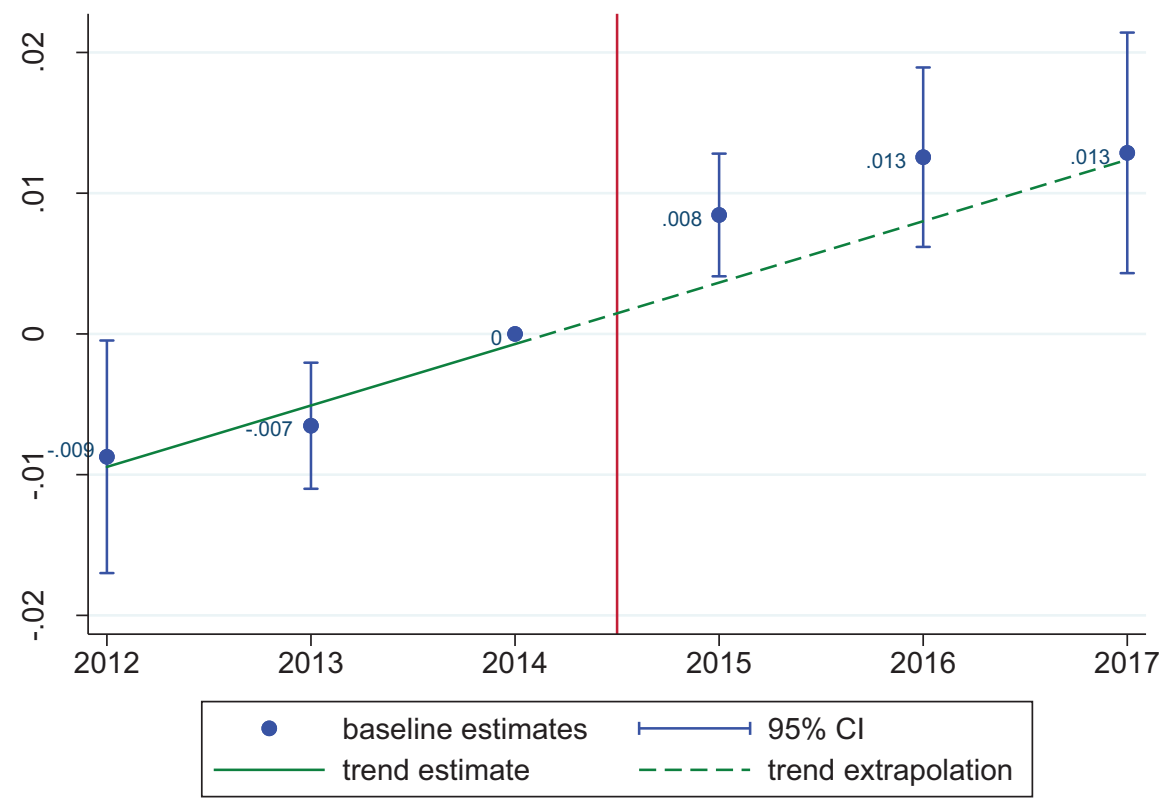

Figure 4: Regression estimates of the effect of the minimum wage on log regular employment in Germany (baseline estimates and underlying trend).

Notes - Figure 4 shows the estimates of the $\delta_{i, j}$ coefficients in eq. (1) (blue dots). They measure how much regular employment changed with every one standard deviation increase in the bite of the minimum wage compared to 2014 (the reference year). The regression includes occupation-, year-, and quarter-fixed effects. The vertical error bars indicate $95 \%$ confidence intervals. The solid green line shows the estimate of a linear bite-proportional time trend based on the pre-reform years 2012-2014. The dashed green line is the extrapolation of this trend for the post-reform years. It represents an estimate of the counterfactual employment trajectory that would have been observed in the absence of the introduction of the minimum wage. The deviations of the post-reform coefficients from the dashed green line may be interpreted as the causal effects of the policy (see Figure 6 for the trend-adjusted point estimates).

Data Sources: Integrated Employment Biographies \& Structure of Earnings Survey 2014, own calculations.

employment. The de-trended effects on marginal employment are still negative, but indistinguishable from zero.

\subsection{Regional heterogeneity}

Looking at West and East Germany separately reveals some interesting differences. In this section, I only discuss the preferred de-trended estimates. The impact of the reform in West Germany (Figure 7) mirrors the results for Germany overall. Regular 


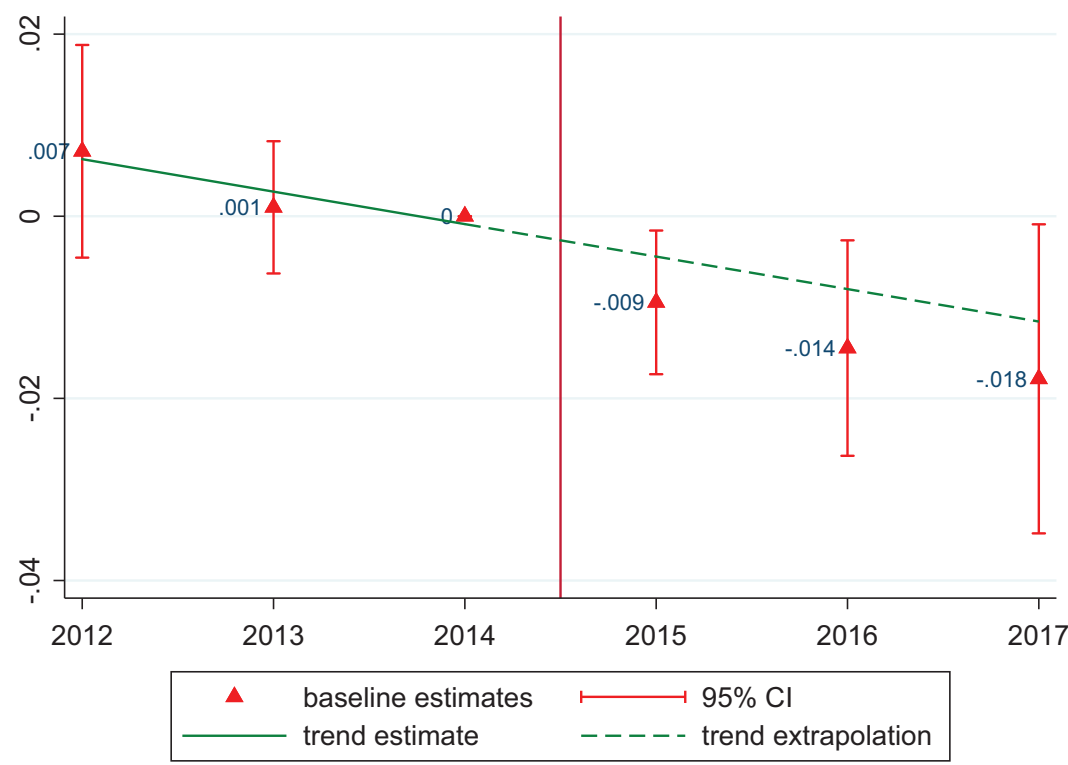

Figure 5: Regression estimates of the effect of the minimum wage on log marginal employment in Germany (baseline estimates and underlying trend).

Notes - Figure 5 shows the estimates of the $\delta_{i, j}$ coefficients in eq. (1) (red triangles). They measure how much marginal employment changed with every one standard deviation increase in the bite of the minimum wage compared to 2014 (the reference year). The regression includes occupation-, year-, and quarter-fixed effects. The vertical error bars indicate $95 \%$ confidence intervals. The solid green line shows the estimate of a linear bite-proportional time trend based on the pre-reform years 2012-2014. The dashed green line is the extrapolation of this trend for the post-reform years. It represents an estimate of the counterfactual employment trajectory that would have been observed in the absence of the introduction of the minimum wage. The deviations of the post-reform coefficients from the dashed green line may be interpreted as the causal effects of the policy (see Figure 6 for the trend-adjusted point estimates).

Data Sources: Integrated Employment Biographies \& Structure of Earnings Survey 2014, own calculations.

employment grew by $0.6 \%$ in response to the reform in the first year, but the effect is zero in 2017. The coefficient estimates for marginal employment are negative, but statistically insignificant. In East Germany, quite the opposite is observed (Figure 8). The effects on regular employment are statistically insignificant while the effects on marginal employment are more strongly negative than in the West and statistically significant. Accordingly, marginal employment in East Germany decreased by $1.4 \%$ in the short run and $3.6 \%$ in the medium run. The latter estimate captures the effect of the 2017 marginal increase of the minimum wage as well. The estimates correspond to a loss of about 20,000 jobs in the short run and 50,000 jobs in the 


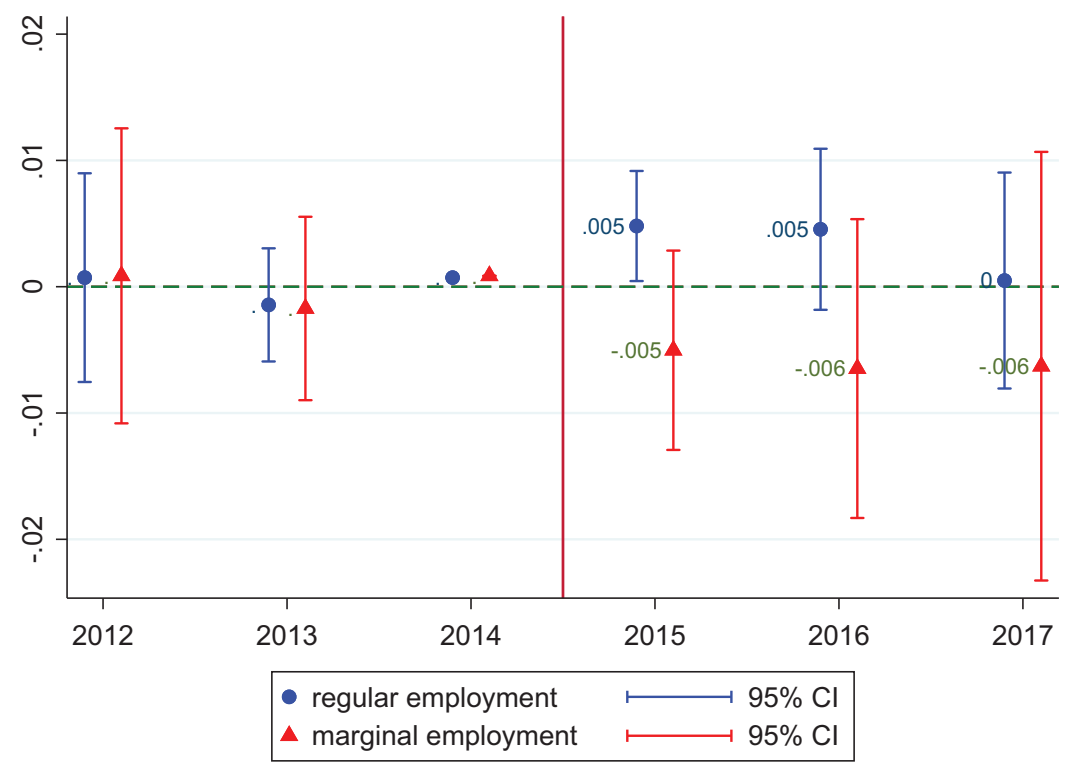

Figure 6: De-trended regression estimates of the effect of the minimum wage on log employment in Germany.

Notes - Figure 6 shows the estimates of the $\delta_{i, j}$ coefficients in eq. (2). They measure how much regular employment (blue dots) and marginal employment (red triangles), respectively, changed with every one standard deviation increase in the bite of the minimum wage compared to 2014 (the reference year). The regressions include occupation-, year-, and quarter-fixed effects as well as a linear bite proportional time trend. The trend-adjusted coefficient estimates can be interpreted as the causal effect of the policy assuming that the pre-reform difference captured by the bite proportional time trend would have continued in the same way in the post-reform period had the minimum wage not been introduced. The vertical error bars indicate $95 \%$ confidence intervals. The estimates refer to Germany as a whole.

Data Sources: Integrated Employment Biographies \& Structure of Earnings Survey 2014, own calculations.

medium run, respectively. Since a positive effect on employment was only identified in West Germany and a negative effect was only identified in East Germany, the East emerges as the loser of the policy from this analysis in terms of employment headcounts.

\subsection{Robustness}

The robustness of the results was assessed in two additional ways. First, the Kaitz index was tested as an alternative treatment variable. It is defined as the 


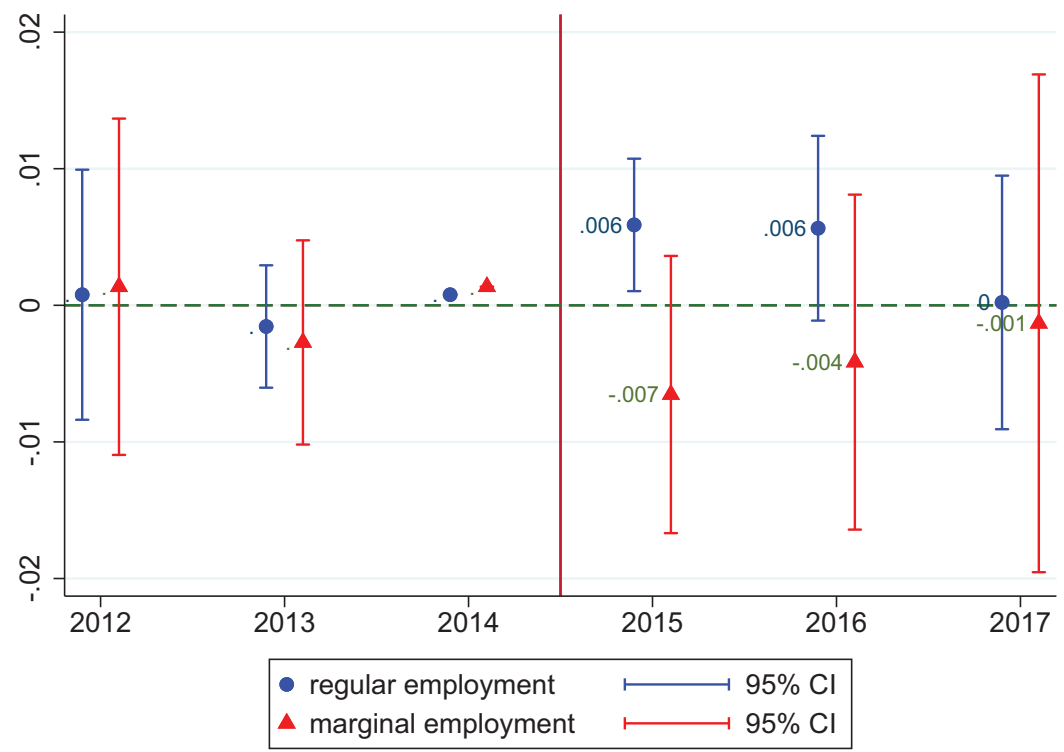

Figure 7: De-trended regression estimates of the effect of the minimum wage on log employment in West Germany.

Notes - Figure 7 shows the estimates of the $\delta_{i, j}$ coefficients in eq. (2). They measure how much regular employment (blue dots) and marginal employment (red triangles), respectively, changed with every one standard deviation increase in the bite of the minimum wage compared to 2014 (the reference year). The regressions include occupation-, year-, and quarter-fixed effects as well as a linear bite proportional time trend. The trend-adjusted coefficient estimates can be interpreted as the causal effect of the policy assuming that the pre-reform difference captured by the bite proportional time trend would have continued in the same way in the post-reform period had the minimum wage not been introduced. The vertical error bars indicate $95 \%$ confidence intervals. The estimates refer to West Germany.

Data Sources: Integrated Employment Biographies \& Structure of Earnings Survey 2014, own calculations.

ratio of the minimum wage to the median hourly wage in each occupation. When the Kaitz index is used, no statistically significant employment effects are observed in West Germany (Figure 9). However, the negative effects on marginal employment in East Germany are also found when changing the treatment variable (Figure 10). The difference in the estimates for West Germany may arise because the two measures rank occupations slightly differently w.r.t. the treatment intensity of the policy. ${ }^{5}$

5 The correlation between the bite and Kaitz index is 0.82 . 


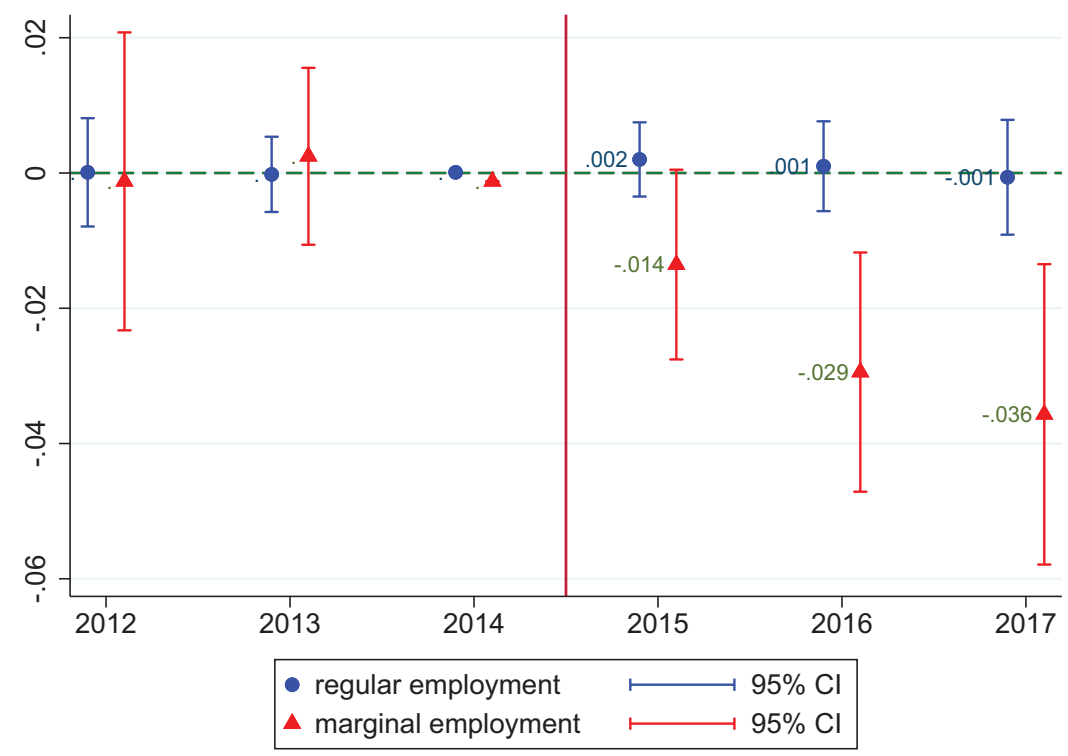

Figure 8: De-trended regression estimates of the effect of the minimum wage on log employment in East Germany.

Notes - Figure 8 shows the estimates of the $\delta_{i, j}$ coefficients in eq. (2). They measure how much regular employment (blue dots) and marginal employment (red triangles), respectively, changed with every one standard deviation increase in the bite of the minimum wage compared to 2014 (the reference year). The regressions include occupation-, year-, and quarter-fixed effects as well as a linear bite proportional time trend. The trend-adjusted coefficient estimates can be interpreted as the causal effect of the policy assuming that the pre-reform difference captured by the bite proportional time trend would have continued in the same way in the post-reform period had the minimum wage not been introduced. The vertical error bars indicate $95 \%$ confidence intervals. The estimates refer to East Germany.

Data Sources: Integrated Employment Biographies \& Structure of Earnings Survey 2014, own calculations.

Secondly, I assessed the functional form of the bite-proportional time trend in eq. (2). To produce the main results, I assumed that the time trend is linear. There is no a priori reason why this should be the case necessarily. To fit higher order trends into the pre-reform period, I estimated treatment effects quarterly (Figure 11). Including a quadratic time trend (bite ${ }^{\star} \mathrm{t}^{2}$ ) in the model, yields a better fit of the pre-treatment differential than using a linear term only. However, the resulting estimated counterfactual for the post-reform period looks very unrealistic and the treatment effects become artificially large. The model including the quadratic trend predicts that without the minimum wage reform regular employment would have decreased by 
$10 \%$ with every one standard deviation increase in the bite of the minimum wage from 2015 to 2016. This prediction seems implausible suggesting that the model over fits the pre-reform data and hence produces an odd forecast for the post-reform period. Therefore, I refrain from using polynomials to control for the underlying trend.

\section{Conclusion}

This paper evaluates the short to medium run employment effects of the 2015 introduction of a statutory minimum wage in Germany. For this purpose, data on employment and wages is analysed at the level of occupations. The analysis shows that the reform had a negligible impact on jobs overall. The average effect, however, masks substantial regional heterogeneity. In West Germany, about 110,000 additional regular jobs were initially created due to the reform. This effect most likely reflects that workers in marginal employment were upgraded to regular jobs because the minimum wage lifted them above the $€ 450$ monthly earnings threshold. This positive effect was temporary, however, and shrunk to zero by the year 2017. This may as well suggest an adverse effect of the first increase of the minimum wage in this year. In East Germany, the policy did not have any positive effects on regular employment, but a negative effect on marginal employment amounting to a loss of about 20,000 jobs in the short run and 50,000 jobs in the medium run. This corresponds to a decline of about $8 \%$ relative to the pre-reform level of marginal employment in East Germany. Thus, from the mere perspective of employment headcounts, East Germany emerges as the loser of the reform.

Compared to ex-ante predictions that at least about 400,000 jobs would be destroyed (Knabe et al. 2014), the job loss estimated in this study may be considered small. Previous ex-post analyses have identified employment effects of similar size. For example, Bossler and Gerner (2019) find that there would have been about 68,000 additional jobs in the absence of the minimum wage reform. My study also adds to previous evidence that adverse employment effects were geographically confined to East Germany (ibid.) and concentrated among marginally employed workers (Caliendo et al. 2018; Schmitz 2019). The finding that regular employment increased initially in response to the reform is in line with extant studies as well (Schmitz 2019; Garloff 2019). Interestingly, I find that the negative effect on marginal employment in East Germany has grown over time and was perhaps intensified by the 2017 increase of the minimum wage that was slightly higher than the inflation rate. This 
result echoes recent evidence for the U.S. labour market showing that the minimum wage may have longer run employment effects (Sorkin 2015; Meer/ West 2016).

As the reform happened in the midst of an extended period of economic expansion, it is important to monitor its impact during the next recession period, when employment responses may increase (Clemens/Wither 2019). Moreover, an important topic for further inquiry are substitution effects since theory predicts that firms substitute capital and higher skilled personnel for low wage workers in response to the introduction of a wage floor (Hamermesh 1996). Recent studies from the U.S. offer evidence for the relevance of these mechanisms (Aaronson/Phelan 2017; Horton 2018).

Acknowledgements: I thankfully acknowledge helpful feedback by Professor Stephen Jenkins (LSE), Professor Regina Riphahn (FAU), Dr Mario Bossler (IAB), Dr David Hendry (LSE) and two anonymous referees. Moreover, I would like to thank seminar participants at the LSE, IAB, IAAE 2019 and EALE 2019 for useful comments. For financial support, I am grateful to the Department of Social Policy at LSE, which sponsored this study through the MSc Conference and Research Fund. Finally, I would like to thank the German Federal Statistical Office and the Institute for Employment Research for providing access to the data.

Funding: This work was supported by the London School of Economics and Political Science (Funder Id: http://dx.doi.org/10.13039/100011326, Grant Number: MSc Conference and Research Fund).

\section{References}

Aaronson, D., B.J. Phelan (2017), Wage Shocks and the Technological Substitution of Low Wage Jobs. The Economic Journal 129: 1-34.

Ahlfeldt, G.M., D. Roth, T. Seidel (2018), The Regional Effects of Germany's National Minimum Wage. Economics Letters 172: 127-130.

Allegretto, S., A. Dube, M. Reich (2011), Do Minimum Wages Really Reduce Teen Employment? Accounting for Heterogeneity and Selectivity in State Panel Data. Industrial Relations: A Journal of Economy and Society 50: 205-240.

Allegretto, S., A. Dube, M. Reich, B. Zipperer (2017), Credible Research Designs for Minimum Wage Studies: A Response to Neumark, Salas, and Wascher. ILR Review 70: 559-592.

Bonin, H., I.E. Isphording, A. Krause-Pilatus, A. Lichter, N. Pester, U. Rinne (2019), The German Statutory Minimum Wage and Its Effects on Regional Employment and Unemployment. Jahrbücher für Nationalökonomie und Statistik, forthcoming. 
Bosch, G. (2018), The Making of the German Minimum Wage: A Case Study of Institutional Change. Industrial Relations Journal 49: 19-33.

Bossler, M., H.-D. Gerner (2019), Employment Effects of the New German Minimum Wage. Evidence from Establishment-Level Micro Data. ILR Review, forthcoming.

Brown, C. (1999), Minimum Wages, Employment and the Distribution of Income. in: 0. Ashenfelter, D. Card (Hrsg.), Handbook of Labor Economics, vol. 3. New York: Elsevier. Burauel, P., M. Caliendo, A. Fedorets, M. Grabka, C. Schroeder, J. Schupp, L. Wittbrodt (2017), Mindestlohn noch längst nicht für alle-Zur Entlohnung anspruchsberechtigter Erwerbstätiger vor und nach der Mindestlohnreform aus der Perspektive Beschäftigter. DIW Wochenbericht 2017 (49): 1109-1123.

Caliendo, M., C. Schroeder, A. Fedorets, M. Preuss, L. Wittbrodt (2017), The Short-Term Distributional Effects of the German Minimum Wage Reform. IZA Discussion Paper 11246.

Caliendo, M., C. Schroeder, A. Fedorets, M. Preuss, L. Wittbrodt (2018), The Short-Run Employment Effects of the German Minimum Wage Reform. Labour Economics 53: 46-62.

Card, D., A.B. Krueger (1994), Minimum Wages and Employment: A Case Study of the Fast Food Industry in New Jersey and Pennsylvania. American Economic Review 84: 772-793.

Card, D., A.B. Krueger (2000), Minimum Wages and Employment: A Case Study of the Fast-Food Industry in New Jersey and Pennsylvania: Reply. American Economic Review 90: 1397-1420.

Cengiz, D., A. Dube, A. Lindner, B. Zipperer (2019), The Effect of Minimum Wages on Low Wage Jobs. Quarterly Journal of Economics 134: 1405-1454.

Clemens, J., M. Wither (2019), The Minimum Wage and the Great Recession: Evidence of Effects on the Employment and Income Trajectories of Low-Skilled Workers. Journal of Public Economics 170: 53-67.

DGB [German Trade Union Confederation] (2015), Mindestlohn wird Armutsrisiko verringern [“The minimum wage will reduce poverty"]. Retrieved on 2019-03-28: http://bit.ly/2BwoVFV.

Dolton, P., C.R. Bondibene, M. Stops (2015), Identifying the Employment Effect of Invoking and Changing the Minimum Wage: A Spatial Analysis of the UK. Labour Economics 37: 54-76.

Dube, A., T.W. Lester, M. Reich (2010), Minimum Wage Effects Across State Borders: Estimates Using Contiguous Counties. The Review of Economics and Statistics 92: 945-964.

Dube, A., T.W. Lester, M. Reich (2016), Minimum Wage Shocks, Employment Flows, and Labor Market Frictions. Journal of Labor Economics 34: 663-704.

Dustmann, C., A. Lindner, U. Schönberg, M. Umkehrer, P. Vom Berge (2019), Reallocation Effects of the Minimum Wage: Evidence from Germany. mimeo.

Dustmann, C., J. Ludsteck, U. Schönberg (2009), Revisiting the German Wage Structure. Quarterly Journal of Economics 124: 843-881.

Federal Emplyoment Agency (2011), Klassifikation der Berufe 2010 - Band 1: Systematischer und alphabetischer Teil mit Erläuterungen. Nuremberg: Federal Emplyoment Agency.

Federal Statistical Office (2016a), Number of Persons in Employment Increased to 43 Million in 2015. Retrieved on 2019-08-28: https://bit.ly/2LcMqVq.

Federal Statistical Office (2016b), 4 Millionen Jobs Vom Mindestlohn Betroffen. Retrieved on 2019-03-28: https://bit.ly/2VbCB09.

Federal Statistical Office (2018), Verdienststrukturerhebung [,structure of Earnings survey“]. For a decription of the data. see: 2019-08-28: http://www.forschungsdatenzentrum.de/ bestand/gls/index.asp.

Federal Statistical Office (2019), Consumer Price Index - Overall Index and by 12 Divisions. Retrieved on 2019-08-28: https://bit.ly/321DX07. 
Garloff, A. (2019), Did the German Minimum Wage Reform Influence (Un)employment Growth in 2015? Evidence from Regional Data. German Economic Review 20: 356-381.

Hamermesh, D.S. (1996), Labor Demand. Princeton: Princeton University Press.

Harasztosi, P., A. Lindner. (2019), Who Pays for the Minimum Wage? American Ecnonomic Review 109: 2693-2727.

Holtemöller, O., F. Pohle (2017), Employment Effects of Introducing a Minimum Wage: The Case of Germany. IWH Discussion Papers 2017/28.

Horton, J.J. (2018), Price Floors and Employer Preferences: Evidence from a Minimum Wage Experiment. mimeo.

Knabe, A., R. Schöb, M. Thum. (2014), Der flächendeckende Mindestlohn. Perspektiven der Wirtschaftspolitik 15: 133-157.

Link, S. (2019), The Price and Employment Response of Firms to the Introduction of Minimum Wages. CESifo Working Paper 7575: 1-56.

Manning, A. (2003), Monopsony in Motion: Imperfect Competition in Labor Markets. Princeton: Princeton University Press.

Matthes, B., W. Paulus (2013), Klassifikation der Berufe. Struktur, Codierung und Umsteigeschlüssel. FDZ-Methodenreport, 2013/8. 1-35. Nürnberg: Bundesagentur für Arbeit.

Meer, J., J. West (2016), Effects of the Minimum Wage on Employment Dynamics. The Journal of Human Resources 51: 500-522.

Mindestlohnkommission (2016), Erster Bericht zu den Auswirkungen des gesetzlichen Mindestlohns. Berlin: Bundesanstalt für Arbeitsschutz und Arbeitsmedizin.

Möller, J., M. König (2008), Ein Plädoyer für Mindestlöhne mit Augenmaß. Ifo Schnelldienst 61: 13-16.

Neumark, D., J.I. Salas, W. Wascher (2014), Revisiting the Minimum Wage-Employment Debate: Throwing Out the Baby with the Bathwater? ILR Review 67 (Supplement): 608-648.

Neumark, D., J.I. Salas, W. Wascher (2017), Reply to "Credible Research Design for Minimum Wage Studies". ILR Review 70: 593-609.

Neumark, D., W. Wascher (1992), Employment Effects of Minimum and Subminimum Wages: Panel Data on State Minimum Wage Laws. ILR Review 46: 55-81.

Neumark, D., W. Wascher (2000), Minimum Wages and Employment: A Case Study of the Fast-Food Industry in New Jersey and Pennsylvania: Comment. American Economic Review 90: 1362-1396.

O’Neill, D., B. Nolan, J. Williams (2006), Evaluating the Introduction of a National Minimum Wage: Evidence from a New Survey of Firms in Ireland. Labour 20: 63-90.

OECD (2019), Decile Ratios of Gross Earnings: Incidence of Low Pay. Retrieved on 2019-03-28: https://bit.ly/2HIUGPT.

Portugal, P., A.R. Cardoso (2006), Disentangling the Minimum Wage Puzzle: An Analysis of Worker Accessions and Separations. Journal of the European Economic Association 4: 988-1013.

Projektgruppe Gemeinschaftsdiagnose (2014), Gemeinschaftsdiagnose Frühjahr 2014: Deutsche Konjunktur im Aufschwung - aber Gegenwind von der Wirtschaftspolitik. Ifo Schnelldienst (2014/8).

Schmitz, S. (2019), The Effects of Germany's New Minimum Wage on Employment and Welfare Dependency. German Economic Review 20: 330-355.

Sorkin, I. (2015), Are There Long-run Effects of the Minimum Wage? Review of Economic Dynamics 18: 306-333.

Stewart, M.B. (2002), Estimating the Impact of the Minimum Wage Using Geographical Wage Variation. Oxford Bulletin of Economics and Statistics 64: 583-605.

Wooldridge, J.M. (2010), Econometric Analysis of Cross Section and Panel Data. Cambridge, Massachusetts: MIT Press (Second edition). 
Article note: This article is part of the special issue "Effects of the Introduction of the Statutory Minimum Wage in Germany" published in the Journal of Economics and Statistics. Access to further articles of this special issue can be obtained at www.degruyter.com/journals/jbnst.

\section{Appendix A}

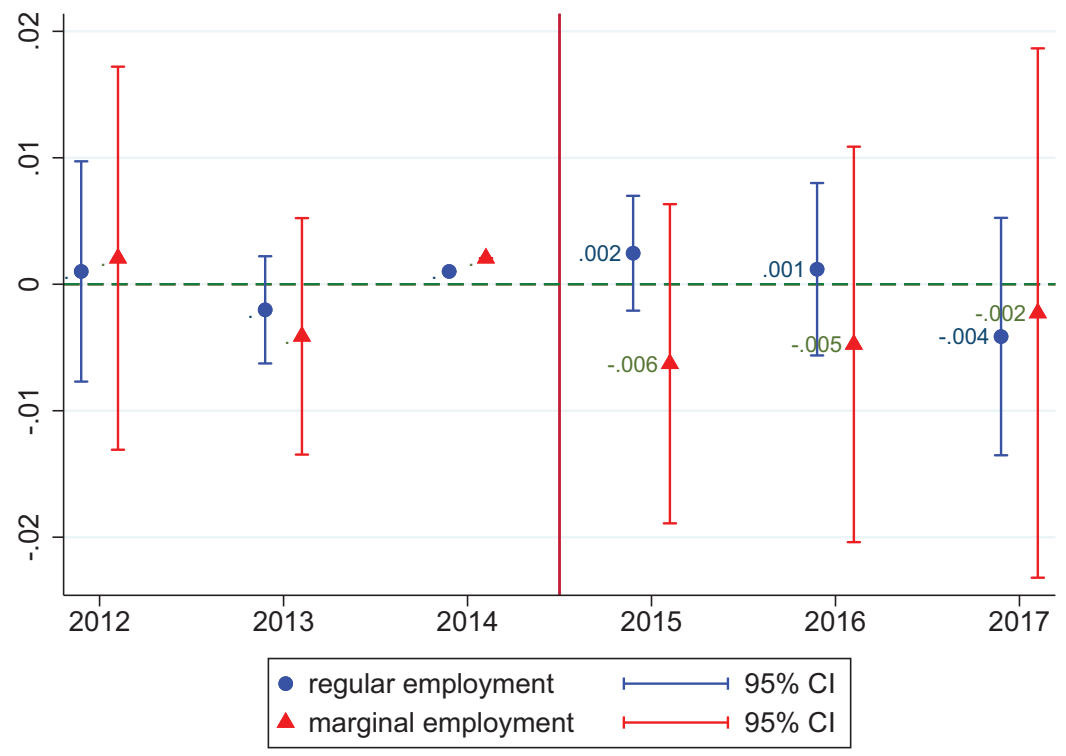

Figure 9: De-trended regression estimates of the effect of the Kaitz index on employment in West Germany.

Notes - Figure 9 shows the estimates of the $\delta_{i, j}$ coefficients in eq. (2). The Kaitz index, which is defined as the ratio of the minimum wage to the median wage in an occupation, was substituted for the bite of the minimum wage. The coefficients measure how much regular employment (blue dots) and marginal employment (red triangles), respectively, changed with every one standard deviation increase in Kaitz index compared to 2014 (the reference year). The regressions include occupation-, year-, and quarter-fixed effects as well as a linear Kaitz-index proportional time trend. The trend-adjusted coefficient estimates can be interpreted as the causal effect of the policy assuming that the pre-reform difference captured by the Kaitz-index proportional time trend would have continued in the same way in the post-reform period had the minimum wage not been introduced. The vertical error bars indicate $95 \%$ confidence intervals. The estimates refer to West Germany.

Data Sources: Integrated Employment Biographies \& Structure of Earnings Survey 2014, own calculations. 


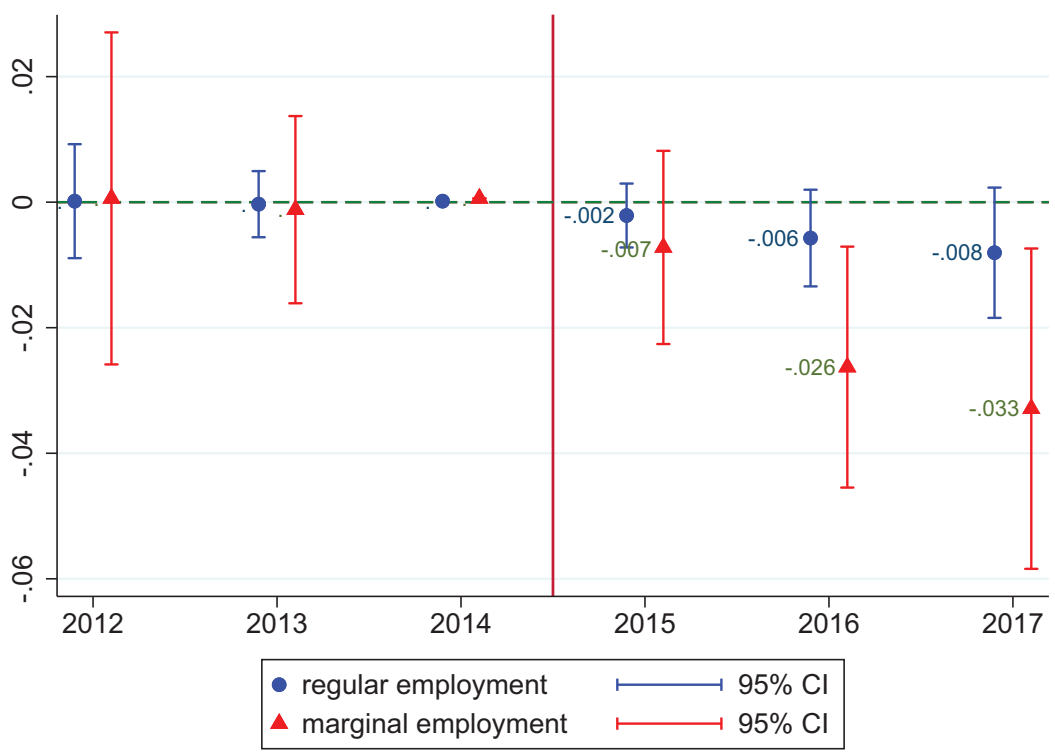

Figure 10: De-trended regression estimates of the effect of the Kaitz index on employment in East Germany.

Notes - Figure 10 shows the estimates of the $\delta_{i, j}$ coefficients in eq. (2). The Kaitz index, which is defined as the ratio of the minimum wage to the median wage in an occupation, was substituted for the bite of the minimum wage. The coefficients measure how much regular employment (blue dots) and marginal employment (red triangles), respectively, changed with every one standard deviation increase in Kaitz index compared to 2014 (the reference year). The regressions include occupation-, year-, and quarter-fixed effects as well as a linear Kaitz-index proportional time trend. The trend-adjusted coefficient estimates can be interpreted as the causal effect of the policy assuming that the pre-reform difference captured by the Kaitz-index proportional time trend would have continued in the same way in the post-reform period had the minimum wage not been introduced. The vertical error bars indicate $95 \%$ confidence intervals. The estimates refer to East Germany.

Data Sources: Integrated Employment Biographies \& Structure of Earnings Survey 2014, own calculations. 


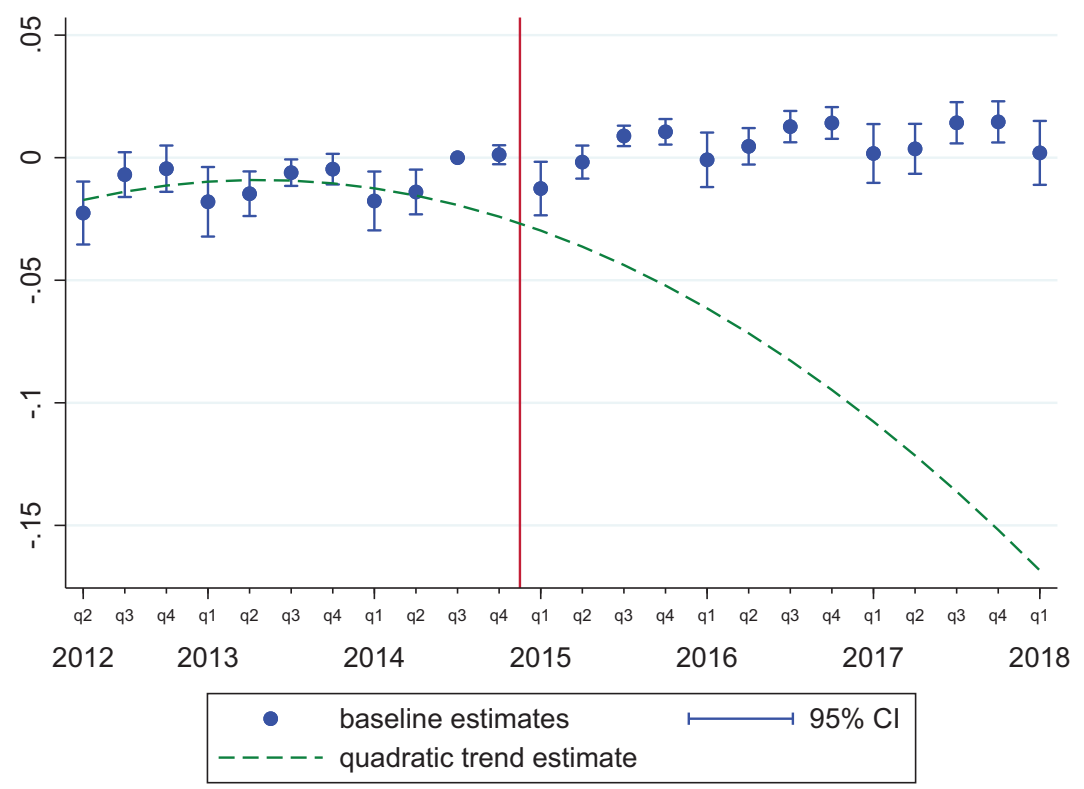

Figure 11: Regression estimates of the effect of the minimum wage on regular employment in Germany (baseline estimates and quadratic trend estimate).

Notes - Figure 11 shows the coefficients estimates of a regression of log regular employment on the bite of the minimum wage interacted with period dummies (blue dots). The regression includes occupation-, year-, and quarter-fixed effects. The vertical error bars indicate $95 \%$ confidence intervals. The reference period is $2014 \mathrm{q} 3$. Furthermore, the figure shows the estimate of a quadratic bite proportional trend based on the pre-reform period (bite*t ${ }^{2}$ ) (dashed line). It reveals that fitting a quadratic trend on the pre-reform data leads to an implausible estimate of the counterfactual employment trajectory that would have been observed in the absence of the introduction of the minimum wage.

Data Sources: Integrated Employment Biographies \& Structure of Earnings Survey 2014, own calculations. 